Ann. Sci. forest., 1981, 38 (1), 55-70

\title{
Perspectives d'application des cultures d'organes in vitro à la multiplication végétative du Pin maritime, Pinus pinaster Sol.
}

\author{
M. RANCILLAC \\ Avec la collaboration technique de P. Lafargue \\ I.N.R.A., \\ Station de Physiologie végétale \\ Centre de Recherches de Bordeaux \\ 33140 Pont-de-la-Maye
}

\section{Résumé}

Chez le Pin maritime, espèce multipliée presque exclusivement par semis faute de techniques efficaces de multiplication végétative, nous avons appliqué les méthodes de culture d'organes in vitro dans le but d'obtenir à court terme des clones à partir de semences sélectionnées et à long terme une méthode de micropropagation de masse.

A partir d'embryons isolés de semences et d'apex entiers prélevés sur des germinations âgées de 6 semaines, nous avons obtenu de nouveaux bourgeons de façon reproductible sous l'influence d'une cytokinine (benzyladénine, $2 \mathrm{mg} / \mathrm{l}$ ).

Des bourgeons, une fois isolés de l'organe originel, ont pu former des racines sous l'influence d'une auxine (acide naphtylacétique, $0,02 \mathrm{mg} / \mathrm{l}$ ); mais la reconstitution de plants entiers n'a pu être obtenue de façon reproductible qu'à partir des bourgeons axillaires d'apex entiers.

Dans l'état actuel de nos essais, une semence peut être dupliquée 8 fois en moyenne dans un laps de temps de 6 mois environ; la méthode doit donc être perfectionnée.

L'observation de racines dichotomisées sur certains plants nous fait envisager la possibilité d'une mycorhization systématique des racines avant la transplantation en serre par des souches fongiques sélectionnées afin de favoriser l'implantation des jeunes arbres.

\section{I. - Introduction}

Les pcuplements de Pin maritime, Pinus pinaster Sol., sont étendus en France, mais souvent de médiocre «qualité ». Aussi des travaux importants d'amélioration génétique ont-ils été entrepris depuis plusieurs années. Mais les résultats sont ralentis par le fait que le Pin est multiplié presque exclusivement par semis. En effet, comme pour de nombreuses autres espèces ligneuses, les méthodes traditionnelles de multiplication végétative par bouturage ne sont pas applicables à un niveau commercial à 
cause du faible pourcentage de réussite. On constate souvent que la rhizogenèse se produit d'autant plus difficilement que le matériel provient d'arbres plus âgés. On surmonte parfois ce problème de «vieillissement» du matériel par des artifices culturaux sur les pieds-mères : prélèvements de rejets de souches pour le Chêne ou le Hêtre (CoRnu et al., 1977), tailles, arcures, incisions annulaires ou néoformations de bourgeons, comme il a été montré dans une synthèse récente (Franclet, 1977), sur d'autres espèces. Mais ces pratiques restent pour l'instant limitées.

C'est pourquoi, nous avons envisagé d'utiliser les techniques de culture de tissus in vitro. Des résultats récents obtenus chez plusieurs conifères nous confortent dans cette voie de recherche. Nous ne citerons que des travaux ayant permis la régénération de plants entiers racinés : Picea abies (Chalupa, 1975), Picea glauca (Campbell \& Durzan, 1975, 1976), Picea sitchensis (Webb \& Street, 1977), Pinus gerardiana (Konar, 1975), Pinus palustris (Sommer \& Brown, 1974 ; Sommer et al., 1975), Pinus pinaster (David \& David, 1977; David et al., 1978), Pinus radiata (Reilly \& Brown, 1976 ; Reilly \& Washer, 1977), Pinus taeda (MotT et al., 1977), Pseudotsuga menziesii (Sommer, 1975 ; Cheng \& Voqui, 1977 ; Boulay \& Franclet, 1977), Tsuga heterophylla (Cheng, 1976), Thuya plicata (Coleman \& Thorpe, 1977).

Au cours de notre expérimentation, nous avons essayé d'abord de déterminer les potentialités organogènes du matériel jeune, puis, de mettre au point une méthode reproductible pour constituer des clones formés de copies-conformes à chaque génotype initial.

\section{II. - Matériel et méthodes}

\section{A. - Matériel végétal}

Des semences du commerce (Coopérative du Sud-Ouest, C.A.F.S.O.), stockées à l'obscurité en chambre froide $\left(+2^{\circ} \mathrm{C}\right)$, sont désinfectées par immersion dans un soluté d'eau oxygénée concentré (110 volumes) et agité pendant 30 minutes; puis elles sont rincées 3 fois à l'eau stérile et placées par deux dans des tubes de verre (diamètre : $22 \mathrm{~mm}$, hauteur : $160 \mathrm{~mm}$ ) sur un milieu solidifié par de l'agar $(8 \mathrm{~g} / 1)$ contenant les macro-éléments de la solution $\mathrm{S}$ ci-dessous.

Les tubes sont obturés par un capuchon métallique non étanche. Après 6 semaines de germination, les plants sont prêts pour l'excision de leurs différents organes : fragments de cotylédons, segments d'axes hypocotylés et radiculaires, apex feuillés entiers avec ou sans les cotylédons et comprenant 3 à $4 \mathrm{~mm}$ d'axe hypocotylé.

Pour la culture des embryons isolés, on procède différemment : les semences sont imbibées dans l'eau stérile à $20^{\circ} \mathrm{C}$, à l'obscurité, pendant 6 à 15 heures, l'aération du milieu étant assurée par agitation de va-et-vient $(100 /$ minute). Puis, après cassage des téguments durs externes et incision des tissus périphériques, on prélève avec une pince fine chaque embryon que l'on ensemence sur le milieu nutritif comprenant une cytokinine. Les tubes sont obturés par un tampon de coton hydrophile et recouverts d'une feuille d'étain ou d'aluminium. 


\section{B. - Environnement climatique : lumière et température}

L'ensemble de l'expérimentation est effectué en chambre climatisée dans les conditions suivantes (sauf mention spéciale dans le texte) :

- la lumière, de type fluorescent, fournit un éclairement au niveau des cultures de 2000 lux environ, pendant 16 heures par cycle de 24 heures;

- la température autour des tubes est maintenue constante à $20^{\circ} \mathrm{C}$ environ.

\section{C. - Composition des milieux nutritifs utilisés}

La composition des milieux nutritifs est donnée dans le tableau 1. Comme milieu de référence, nous avons employé la solution de Murashige \& SKoog (1962), légèrement modifiée, dénommée «solution $M »$. Les autres milieux utilisés en comparaison sont dénommés «solution $S$ » (macro-éléments de Risser \& WHITE, 1964, modifiés par Sommer et al., 1975) et «solution $H$ » (micro-éléments de la solution de Heller, 1953).

\section{Tableau 1}

Composition des milieux nutritifs utilisés

Composition of nutritive solutions

1. Sels minéraux : macro-éléments en $\mathrm{mg} / \mathrm{l}$

Mineral salts : major elements (mg/l)

\begin{tabular}{|c|c|c|c|}
\hline \multicolumn{2}{|c|}{ Solution de référence $\mathbf{M}$} & \multicolumn{2}{|l|}{ Solution $\mathrm{S}$} \\
\hline $\mathrm{NH}_{4} \mathrm{NO}_{3}$ & 1650 & $\mathrm{Ca}\left(\mathrm{NO}_{3}\right)_{2}, 4 \mathrm{H}_{2} \mathrm{O}$ & 300 \\
\hline $\mathrm{KNO}_{3}$ & 1900 & $\mathrm{KNO}_{3} \ldots \ldots \ldots$ & 80 \\
\hline $\mathrm{CaCl}_{2}, 2 \mathrm{H}_{2} \mathrm{O}$ & 440 & $\mathrm{KCl} \ldots$ & 65 \\
\hline $\mathrm{MgSO}_{4}, 7 \mathrm{H}_{2} \mathrm{O}$ & 370 & $\mathrm{MgSO}_{4}, 7 \mathrm{H}_{2} \mathrm{O}$ & 740 \\
\hline $\mathbf{K H}_{2} \mathbf{P O}_{4} \ldots \ldots \ldots \ldots$ & 170 & $\mathrm{NaH}_{2} \mathrm{PO}_{4}, \mathrm{H}_{2} \mathrm{O}$ & 165 \\
\hline & & $\mathrm{Na}_{2} \mathrm{SO}_{4}, 10 \mathrm{H}_{2} \mathrm{O}$ & 450 \\
\hline
\end{tabular}

2. Sels minéraux : micro-éléments en $\mathrm{mg} / \mathrm{l}$

Mineral salts : minor elements $(\mathrm{mg} / \mathrm{l})$

\begin{tabular}{|c|c|c|c|}
\hline \multicolumn{2}{|l|}{ Solution de référence $\mathbf{M}$} & \multicolumn{2}{|l|}{ Solution $\mathrm{H}$} \\
\hline $\mathrm{H}_{3} \mathrm{BO}_{3} \ldots \ldots \ldots \ldots$ & 6,2 & $\mathrm{H}_{3} \mathrm{BO}_{3} \ldots \ldots$ & 1 \\
\hline $\mathrm{MnSO}_{1}, 4 \mathrm{H}_{2} \mathrm{O} \ldots \ldots$ & 22,3 & $\mathrm{MnSO}_{4}, 4 \mathrm{H}_{2} \mathrm{O}$ & 0,1 \\
\hline $\mathrm{ZnSO}_{4}, 7 \mathrm{H}_{2} \mathrm{O} \ldots \ldots$ & 8,6 & $\mathrm{AlCl}_{3}, \ldots \ldots \ldots \ldots$ & 0,03 \\
\hline KI $\ldots \ldots \ldots \ldots \ldots$ & 0,83 & KI . . & 0,01 \\
\hline $\mathrm{Na}_{3} \mathrm{MoO}_{4}, 2 \mathrm{H}_{2} \mathrm{O} \ldots \ldots$ & 0,25 & $\mathrm{NiCl}_{2}, 6 \mathrm{H}_{2} \mathrm{O}$ & 0,03 \\
\hline $\mathrm{CuSO}_{4}, 5 \mathrm{H}_{2} \mathrm{O} \ldots \ldots$ & 0,025 & $\mathrm{CuSO}_{4}, 5 \mathrm{H}_{2} \mathrm{O}$ & 0,03 \\
\hline $\mathrm{CoCl}_{2}, 6 \mathrm{H}_{2} \mathrm{O} \ldots \ldots \ldots$ & 0,025 & $\mathrm{FeCl}_{3}, 6 \mathrm{H}_{2} \mathrm{O} \ldots \ldots \ldots$ & 1 \\
\hline Fer $\left(^{*}\right) \ldots \ldots$ & 15 & & \\
\hline
\end{tabular}

$\left(^{*}\right)$ Citrate de fer ammoniacal, brun. Ammonium ferric citrate, brown. 
3. Constituants organiques

Organic constituents

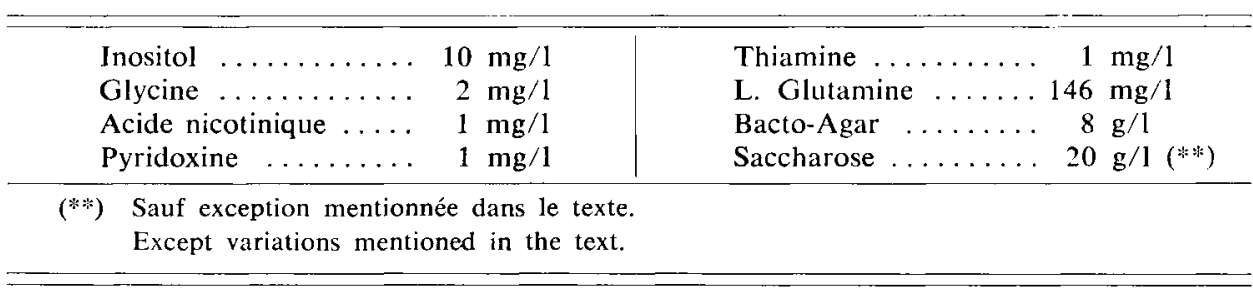

Le pH des milieux est ajusté à 5,5 après addition de tous les composés, y compris les régulateurs de croissance.

La stérilisation se fait par autoclavage à 115 "C pendant 20 minutes.

\section{III. - Résultats expérimentaux}

La démarche que nous avons suivie est celle-ci : dans un premier temps, induire ou stimuler le développement de nouveaux bourgeons (phase de caulogenèse), puis isoler ces bourgeons et, dans un deuxième temps, provoquer leur enracinement (phase de rhizogenèse) de façon à reconstituer des plants entiers autonomes.

D'après la littérature et nos travaux antérieurs (MARgara \& Rancillac, 1966), nous savons que parmi les facteurs exogènes les plus importants pour l'expression des potentialités organogènes des tissus, deux groupes prédominent : les régulateurs de croissance, en particulier les auxines et les cytokinines, et les facteurs nutritifs, en particulier les sels minéraux (MUrashige \& SKoog, 1962) et les glucides assimilables. Dans nos essais sur le Pin maritime, ce sont donc essentiellement ces deux groupes de facteurs dont nous avons analysé le rôle de façon qualitative et quantitative sur chaque type de matériel, à chaque phase de la culture (caulogenèse et rhizogenèse).

\section{A. - Phase de caulogenèse : induction ou stimulation du bourgeonnement}

\section{Action des régulateurs de croissance}

La présence d’une cytokinine s'est révélée déterminante pour induire la caulogenèse ; la benzyladénine est plus efficace que la kinétine. Une concentration comprise entre 2 et $4 \mathrm{mg} / 1$ est la plus favorable.

- Sur des embryons matures (photo 1), comme sur des segments d'hypocotyles et de cotylédons ou des cotylédons entiers, les bourgeons sont néoformés à partir de cals. Sur les embryons, on peut noter de 20 à 40 méristèmes.

- Sur des apex entiers isolés de jeunes germinations, les bourgeons se développent à l'aisselle des feuilles juvéniles et des cotylédons (photo 2) à partir des méristèmes axillaires préformés. On note de 6 à 18 bourgeons. 


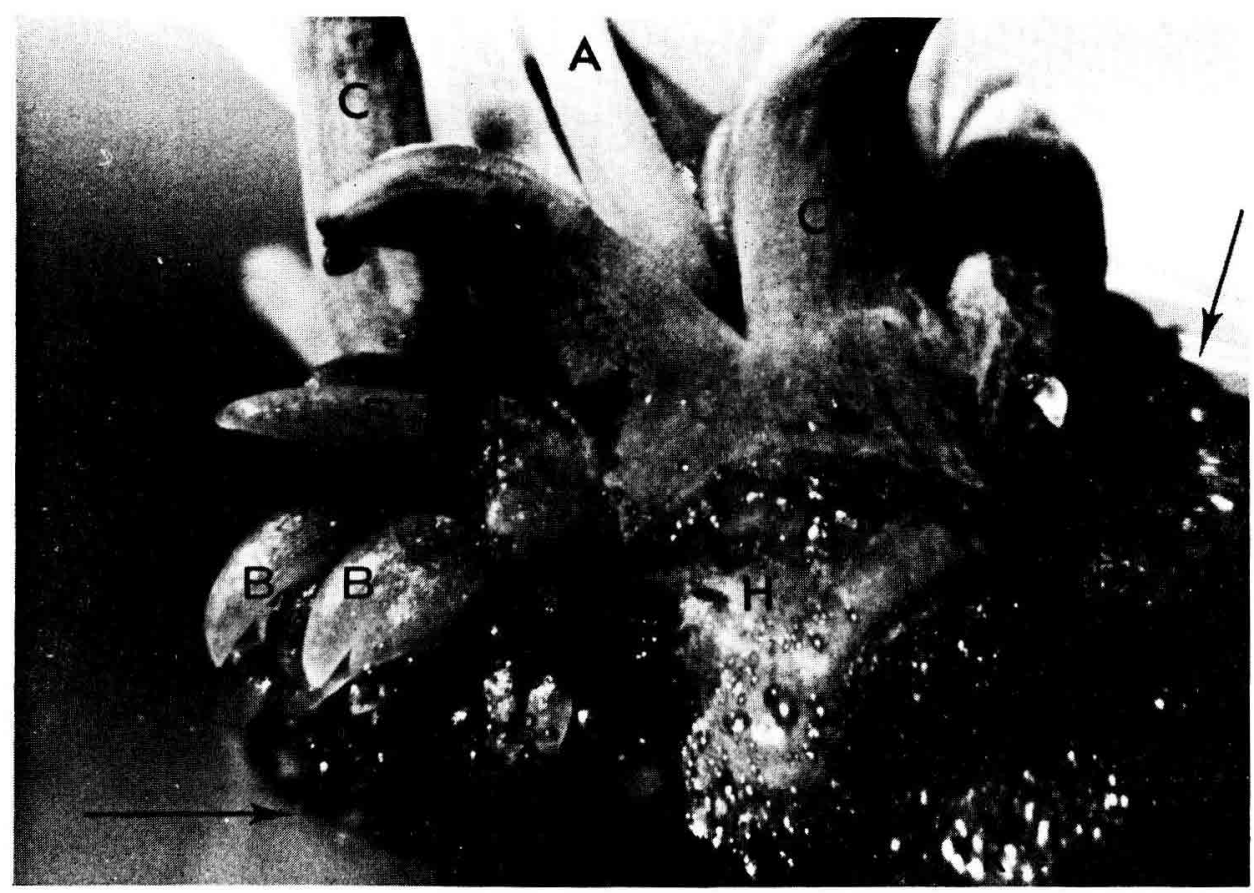

Рното 1

Néoformation de bourgeons (B) au contact du milieu de culture (flèches) et sur la face dorsale des cotylédons (C) d'un embryon excisé d'une semence et cultivé en présence d'une cytokinine pendant 6 semaines ( $A=$ bourgeon apical $; H=$ hypocotyle $; R=$ radicule)

Adventitious cytokinin-induced budding of an excised embryo after a 6-week period. New buds, B, come out from superficial tissues of hypocotyl axis, $\mathrm{H}$, in contact with the medium $(\rightarrow)$ and back-faces of cotyledons, $C$ ( $A=$ apical bud $; R=$ primary root)

Les auxines, AIA, AIB, ANA, ne sont pas indispensables au bourgeonnement et favorisent plutôt la croissance des cals. L'acide gibbérellique montre une action défavorable.

\section{Action des facteurs de la nutrition}

Nous avons observé que la formation des bourgeons axillaires sur les touffes apicales nécessite un niveau d'éléments minéraux plus élevé (solution $M$ ) que pour des bourgeons néoformés sur des embryons (solution $S$ pour les macro-éléments, et solution $M$ diluée de moitié pour les micro-éléments, les additifs organiques restant inchangés). Les exigences des deux types de matériels sont donc différentes. Par contre, l'optimum en saccharose se situe aux environs de $20 \mathrm{~g} / 1$ pour les divers matériels. 


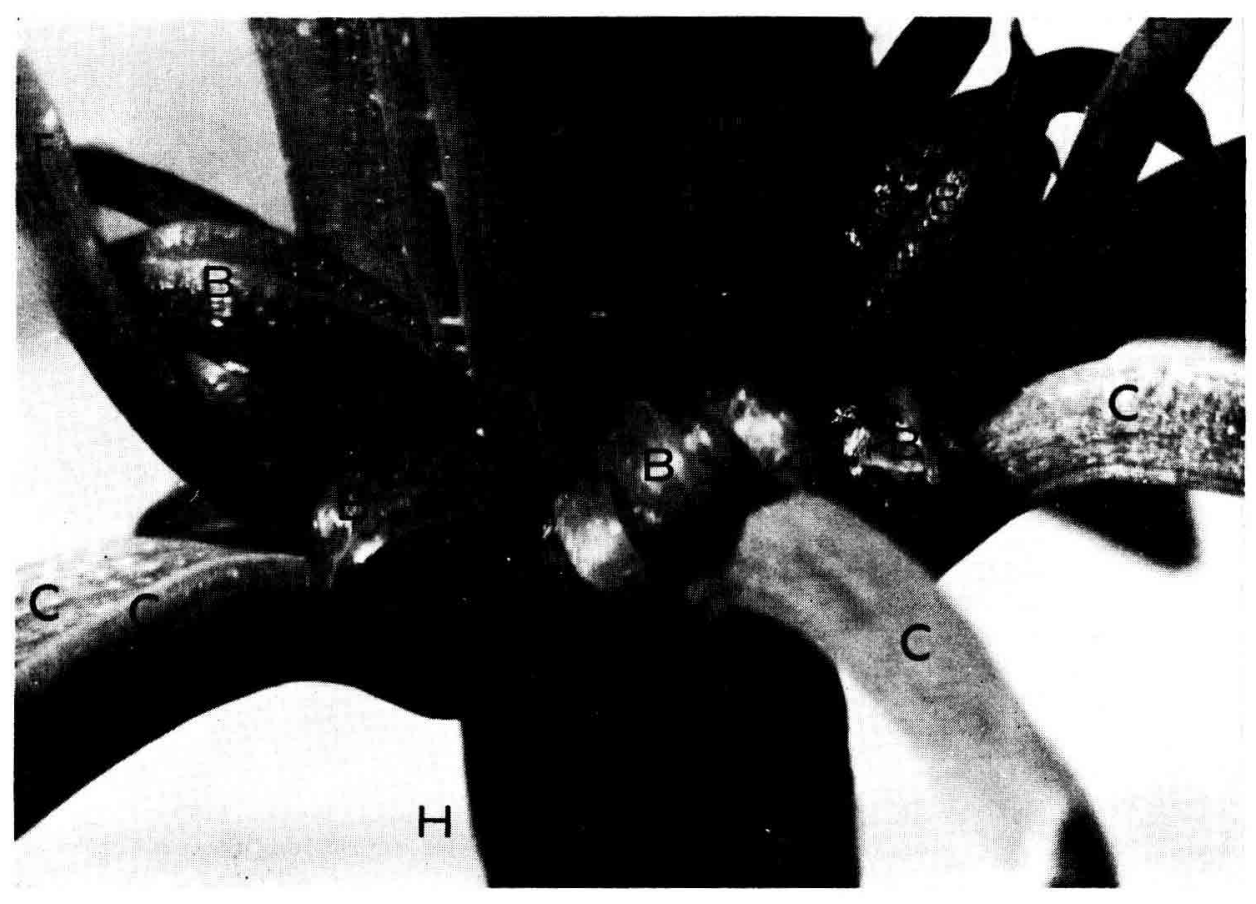

Рното 2

Développement des bourgeons axillaires $(B)$ à l'aisselle des cotylédons $(C)$ et des jeunes feuilles $(F)$ d'un apex entier cultivé en présence d'une cytokinine pendant 6 semaines $(H=$ axe hypocotylé)

Axillary cytokinin-promoted budding of a seedling shoot tip after a 6-week period ( $C=$ cotyledons, $F=$ young leaves, $H=$ hypocotyl axis)

\section{Action de la lumière et de la température}

La lumière s'est révélée indispensable à la caulogenèse dans nos conditions expérimentales, les cultures à l'obscurité formant un cal qui brunit ensuite et se nécrose. Nous avons essayé par ailleurs d'accélérer le développement des bourgeons en élevant la température : une température de $25^{\circ} \mathrm{C}$ favorise mieux la croissance des bourgeons que $20^{\circ} \mathrm{C}$.

\section{Conclusion}

Pour obtenir une caulogenèse importante il faut faire agir ensemble plusieurs facteurs exogènes : une cytokinine, un milieu nutritif enrichi en éléments minéraux et organiques où les glucides doivent jouer un rôle énergétique essentiel, et une température élevée. Mais les divers organes peuvent avoir des exigences particulières en tel ou tel élément pour exprimer leurs potentialités. Ainsi, de tous les matériels mis en culture, seuls les embryons isolés et les apex entiers ont pu donner de façon repro- 
ductible une caulogenèse intense et des bourgeons suffisamment développés pour être isolés et transférés sur des milieux propres à la rhizogenèse. Les autres organes ont formé de petits cals avec parfois un bourgeonnement, mais de façon aléatoire (tableau 2).

\section{TABleau 2}

Poientialités organogènes, intensité et reproductibilité des phénomènes observés dans nos conditions expérimentales

Organogene ic potentialities, intensity and reproducibility of phenomena observed in our experimental conditions

\begin{tabular}{|c|c|c|c|}
\hline \multirow{2}{*}{$\begin{array}{l}\text { Nature des cxplantats } \\
\text { Nature of explants }\end{array}$} & \multicolumn{3}{|c|}{$\begin{array}{l}\text { Organogenèse observée } \\
\text { Observed organogenesis }\end{array}$} \\
\hline & $\begin{array}{l}\text { Cals } \\
\text { Callus }\end{array}$ & $\begin{array}{l}\text { Bourgeons } \\
\text { Buds (a) }\end{array}$ & $\begin{array}{l}\text { Racines } \\
\text { Roots (b) }\end{array}$ \\
\hline $\begin{array}{l}\text { Embryons matures } \\
\text { Mature embryos }\end{array}$ & +++ (c) & +++ & + \\
\hline $\begin{array}{l}\text { Segments racines } \ldots \\
\text { Root segments }\end{array}$ & ++ & $?$ & + \\
\hline $\begin{array}{l}\text { Segments hypocotyles } \ldots . \\
\text { Hypocotyl segments }\end{array}$ & ++ & + & $?$ \\
\hline $\begin{array}{l}\text { Segments cotylédons } \ldots \ldots \ldots \\
\text { Cotyledon segments }\end{array}$ & ++ & + & $?$ \\
\hline $\begin{array}{l}\text { Cotylédons entiers } \ldots \\
\text { Entire cotyledons }\end{array}$ & + & + & $?$ \\
\hline $\begin{array}{l}\text { Apex entiers } \ldots \ldots \ldots \ldots \ldots \\
\text { Shoot tips }\end{array}$ & + & +++ & +++ \\
\hline
\end{tabular}

(a) Bourgeons adventifs néoformés ou bourgeons axillaires.

(b) Racines adventives néoformées ou racines secondaires.

(c) +++ : Formation intense et reproductible.

$+\quad$ : Formation assez intense, mais plus ou moins reproductible.

$+\quad$ : Formation peu intense et peu reproductible.

? : Formetion non encore observée.

(a) Adventitious or axillary buds.

(b) Adventitious or secondary roots.

(c) +++ : Very intensive and reproducible.

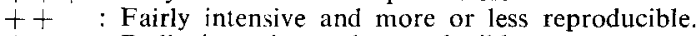

$+\quad$ : Badly intensive and reproducible.

? $\quad$ : Unobserved so far. 


\section{B. - Phase de rhizogenèse : \\ induction des racines sur les bourgeons isolés}

\section{Action des régulateurs de croissance}

La présence d’une auxine a été déterminante pour induire la rhizogenèse, mais seuls (tableau 2) les bourgeons axillaires isolés des touffes apicales de jeunes germinations se sont révélés aptes à l'enracinement de façon reproductible (photo 3). Les bourgeons néoformés à partir des tissus des embryons n'ont donné que 2 enracinements sur près de 100 bourgeons isolés. Par ordre d'efficacité et de reproductibilité des résultats, nous avons ANA $>$ AIB $>$ AIA. De plus, la «qualité » de l'enracinement varie selon la concentration utilisée (tableau 3). Les grosses racines sont courtes, très peu ramifiées et entraînent une mortalité importante des plants au repiquage par contamination fongique ou mauvais raccordement vasculaire avec le bourgeon. Par contre, les racines fines s'allongent et se ramifient facilement assurant une reprise des plants de l'ordre de 80 à 90 p. 100.

Les cytokinines ont été défavorables et l'acide gibbérellique s'est montré sans effet durant la phase de rhizogenèse.

\section{Tableau 3}

Efficacité comparée des concentrations d'AlB et d'ANA

sur le pourcentage de bourgeons cnracinés et la qualité de l'enracinement

Comparative effects of $I B A$ and NAA concentrations on rooting percentage and quality

\begin{tabular}{|c|c|c|}
\hline $\begin{array}{c}\text { Type et concentration d'auxine } \\
\text { Auxin nature } \\
\text { and concentration }\end{array}$ & $\begin{array}{l}\% \text { d'enracinements } \\
\% \text { rooting }\end{array}$ & $\begin{array}{l}\text { Qualité de l'enracinement } \\
\text { Rooting quality }\end{array}$ \\
\hline ANA $0,02 \mathrm{mg} / 1$ (1) $\ldots \ldots \ldots$ & $50(a)-100(b)$ & $\begin{array}{l}1 \text { à } 2 \text { racines fines par bour- } \\
\text { geon }\end{array}$ \\
\hline ANA $\quad 0,2 \quad \mathrm{mg} / 1$ & $30-50$ & $\begin{array}{l}\text { Formation d'un cal, puis de } 3 \text { à } \\
6 \text { racines de gros diamètre } \\
\text { par bourgeon }\end{array}$ \\
\hline AIB $0,2 \mathrm{mg} / \mathrm{l}(1) \ldots \ldots \ldots$ & $20-40$ & $\begin{array}{l}1 \text { à } 2 \text { racines fines par bour- } \\
\text { geon }\end{array}$ \\
\hline AIB $0,02 \mathrm{mg} / 1(1) \ldots \ldots \ldots$ & $2-10$ & $\begin{array}{l}1 \text { à } 2 \text { racines fines par bour- } \\
\text { geon }\end{array}$ \\
\hline Témoin sans auxine $\ldots$. & 0 & \\
\hline
\end{tabular}

(1) L'auxine est maintenue durant toute la durée de l'expérience.

(2) L'auxine est maintenue les 10 à 15 premiers jours, puis les cultures sont transférées sur un milieu sans auxine.

(a) Le premier nombre correspond au pourcentage moyen de bourgeons enracinés prélevés sur différents axes dans 3 essais différents.

(b) Le second nombre indique le pourcentage maximum observé de bourgeons enracinés prélevés sur un même axe dans un essai donné.

(1) Auxin added all along the culture period.

(2) Auxin added the first 10-15 days, then subculture without auxin.

(a) Mean percentage of rooting on buds excised from many shoot tips in 3 different replications.

(b) Maximum percentage of rooting on buds excised from the same shoot tip. 


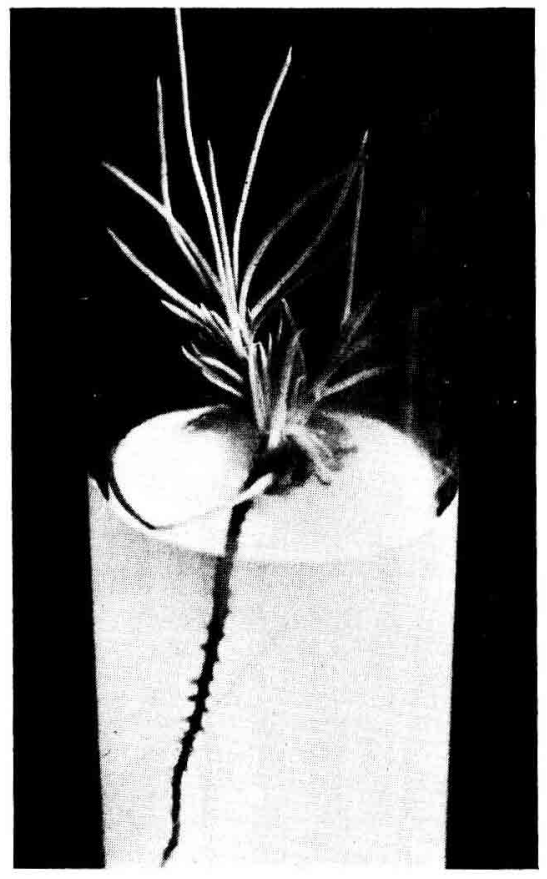

Phoio 3

Enracinement diun bourgeon axillaire isolé de la touffe apicale et cultivé en présence d'une auxine pendant 8 semaines (le diamètre du tube, $22 \mathrm{~mm}$, donne l'échelle)

Auxin-induced rooting of an excised axillary bud after a 8-week period (scale: test-tube diameter, $22 \mathrm{~mm}$ )

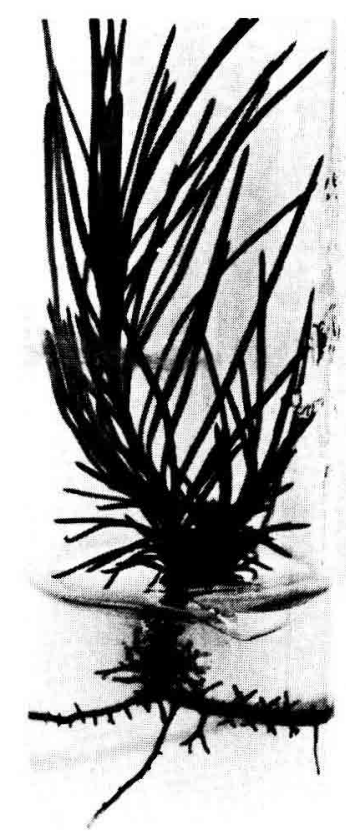

Рното 4

Formation de racines secondaires dichotomisées sur l'appareil racinaire néoformé à partir d'un bourgeon axillaire isolé (le diamètre du tube, $22 \mathrm{~mm}$, donne l'échelle)

Dichotomous secondary root formation on the new rooting system of an excised axillary bud (test-tube diameter, $22 \mathrm{~mm}$ )

2. Action des facteurs de la nutrition

Des essais comparatifs avec diverses compositions des milieux nutritifs ont montré pour les deux types de bourgeons, néoformés et axillaires, que :

- les macro-éléments de la solution $S$ sont préférables à ceux de la solution $\mathrm{M}$;

- les micro-éléments de la solution $H$ sont préférables à ceux de la solution de référence $M$, ou $M$ diluée de moitié.

Le seuil nutritif requis pour la rhizogenèse est donc plus faible que celui exigé pour la caulogenèse. Cela se traduit aussi par le fait que 5 à $10 \mathrm{~g} / \mathrm{l}$ de saccharose sont suffisants pour la rhizogenèse.

\section{Action d'autres facteurs}

L'exigence thermique semble inféricure à celle de la caulogenèse puisquiune température de $20^{\circ} \mathrm{C}$ est plus favorable à la formation des racines que $25^{\circ} \mathrm{C}$. 


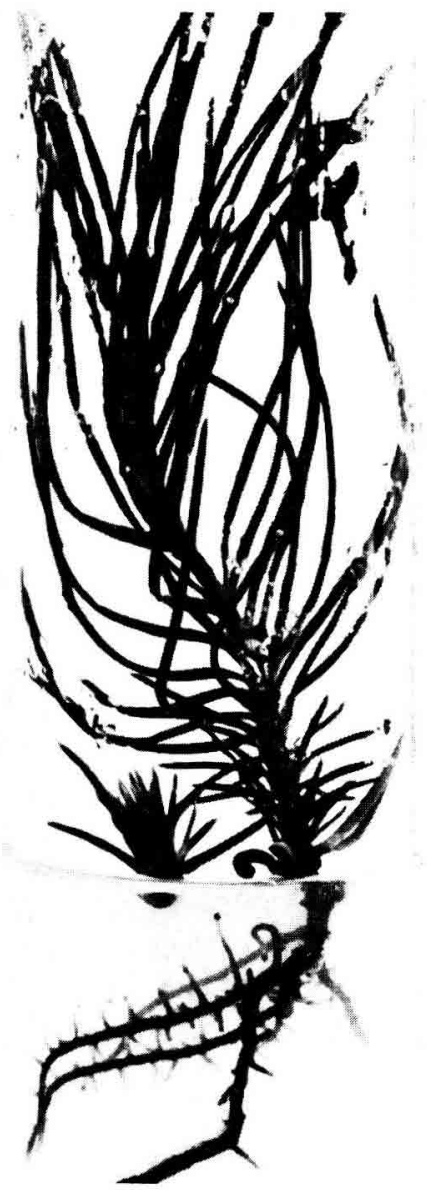

\section{Рното 5}

Jeune plant développé à partir d'un bourgeon axillaire isolé et prêt à être repiqué en serre; la tige s'est allongée fortement et l'appareil racinaire s'est ramifié (le diamètre du tube, $22 \mathrm{~mm}$, donne l'échelle; noter que le bourgeon de gauche dans le tube n'a pas produit de racine)

A new seedling with good stem elongation and root ramification was rebuilt in test-tube from an excised axillary bud; it is ready for greenhouse transplantation. The bud on the left is without rooting (test-tube diameter, $22 \mathrm{~mm}$ )

Рното 6

Jeune plant de Pin maritime obtenu in vitro et cultivé en serre depuis 2 mois (hauteur de la tige, $10 \mathrm{~cm}$ environ)

Behaviour of a new Pinus seedling 2 months after greenhouse transplantation from the test-tube (stem length, \# $10 \mathrm{~cm}$ )
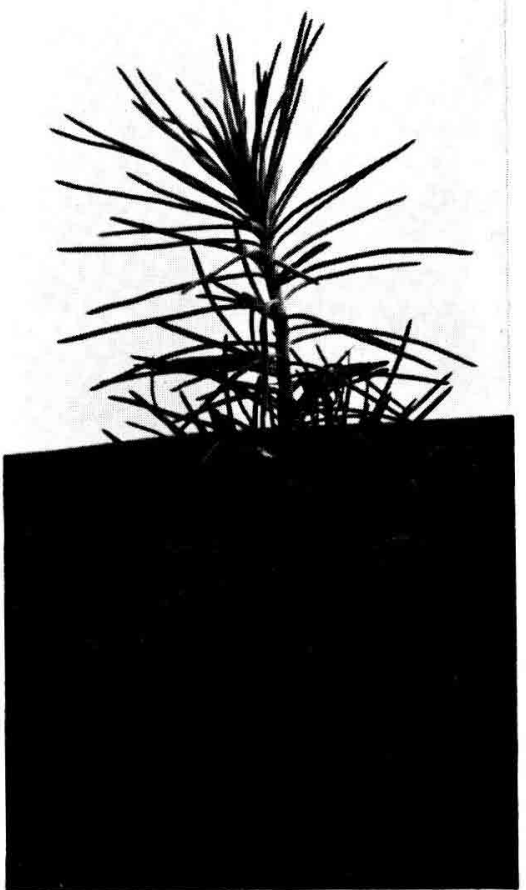
Nous avons vérifié par aillcurs que le niveau d'insertion des bourgeons sur laxe épicotylé, depuis le plan cotylédonnaire jusqu’à l'apex, n’a pas d’influence sur les potentialités de rhizogenèse de ces bourgeons. Par contre, les petits bourgeons ou les bourgeons isolés trop tôt ne donnent généralement pas de racines. Il semble bien que le stade de développement atteint par les bourgeons soit important pour leur aptitude à la rhizogenèse. Ce point reste à préciser pour pouvoir quantifier la méthode.

\section{Morphologie particulière des systèmes racinaires}

Il arrive parfois que l'on observe, sur les racines principales néoformées, des racines secondaires courtes et bifurquées; celles-ci (photo 4), d'aspect dichotome, peuvent se ramifier à nouveau prenant une forme corallö̈de. Ce phénomìne est intéressant car on sait quiil se produit dans les conditions naturelles lorsque les racines du Pin sont colonisées par des champignons dits mycorhiziens et que s'établit une symbiose entre les deux organismes. Or, dans nos conditions de culture in vitro, aucune contamination exogène de type fongique n'est observée, ce qui pose la question du déterminisme de la formation de ces racines courtes dichotomisées.

\section{Conclusion}

Pour induire la rhizogenèse, une auxine exogène semble l'un des facteurs les plus importants. Mais, dans nos conditions expérimentales, un seul matériel, les bourgeons axillaires isolés des touffes apicales entières, est capable de néoformer des racines de façon reproductible (tableau 2). Ces racines deviennent visibles entre 3 et 6 semaines à partir du début du traitement auxinique. Selon les touffes apicales, le nombre de bourgeons isolés qui s’enracinent, exprimé en pourcentage, varie de 50 à 100 p. 100 . On obtient pour linstant en moyenne 8 bourgeons enracinés par touffe. Avant la transplantation en serre, il convient de laisser lappareil racinaire se développer pendant encore un ou deux mois sur le même milieu de culture. Durant cette période, la tige s'allonge et c’est un plant déjà bien constitué (photo 5) que l’on repique alors sans difficulté (photo 6).

\section{IV. - Conclusion générale et discussion}

A partir de jeunes plants issus de semences, nous avons montré qu'il est possible de stimuler le développement des bourgeons axillaires formés sur l'axe principal à l'aisselle des feuilles juvéniles et des cotylédons, d'isoler ces bourgeons et de provoquer leur cnracinement.

Par cette méthode, que nous avons résumée dans un schéma général (figure 1), chaque semence peut donner non plus un plant unique, mais plusieurs copies de ce plant formant alors un clone. Pour l'instant, le nombre de copies est encore restreint (8 par clone en moyenne); des essais sont en cours pour augmenter l'efficacité de la méthode : en précisant les stades de développenent optimum à chaque étape de la culture et en obtenant plusieurs générations successives de bourgeons aptes à s'enraciner. 

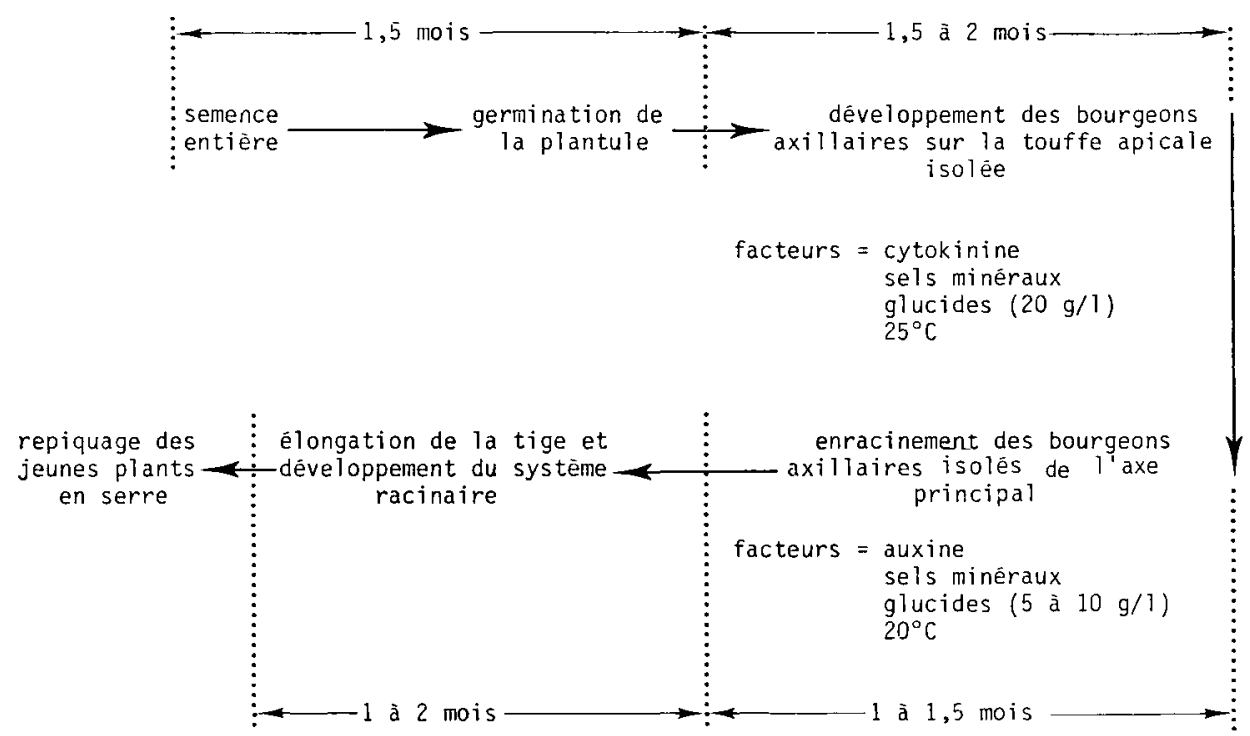

FIG. 1

Schéma d'ensemble de la production de plants racinés in vitro à partir de semences entières (durée d'un cycle complet : 5 à 7 mois)

Steps in the tissue culture micropropagation of pine

(time lapse between seed culture and greenhouse transplantation of the Ist generation of new plants is 5-7 months)

D’autres essais à partir de génotypes sélectionnés permettront également de vérifier la généralisation de la méthode et de mieux quantifier d'une part la réaction individuelle, d'autre part la réaction de chaque famille, comme cela a été fait pour Pinus taeda (Мотт et al., 1977). Nous étudierons également les possibilités de mycorhization in vitro des racines par des souches fongiques sélectionnées pour vérifier si ce traitement favorise l'implantation et la croissance ultérieure des jeunes Pins.

Ces différents points feront l'objet de publications ultérieures.

Si lon compare les parties aériennes des plants obtenus in vitro avec celles de boutures de «brachyblastes allongés» après taille des pieds-mères, on remarque les caractéristiques suivantes (photo 7) : les boutures issues de la multiplication végétative de «brachyblastes allongés » gardent l'aspect déjà adulte des pieds-mères, et cela même si l'on effectue un nouveau bouturage à partir de la pousse de lannée de la première bouture; aucun caractère de «re-juvénilisation» ne se manifeste (RANCiLlac, résultat non publié); par contre, tous les plants issus de la multiplication végétative in vitro présentent les caractéristiques juvéniles des plantules dont ils sont issus (présence d'euphylles le long de laxe principal, en particulier). 


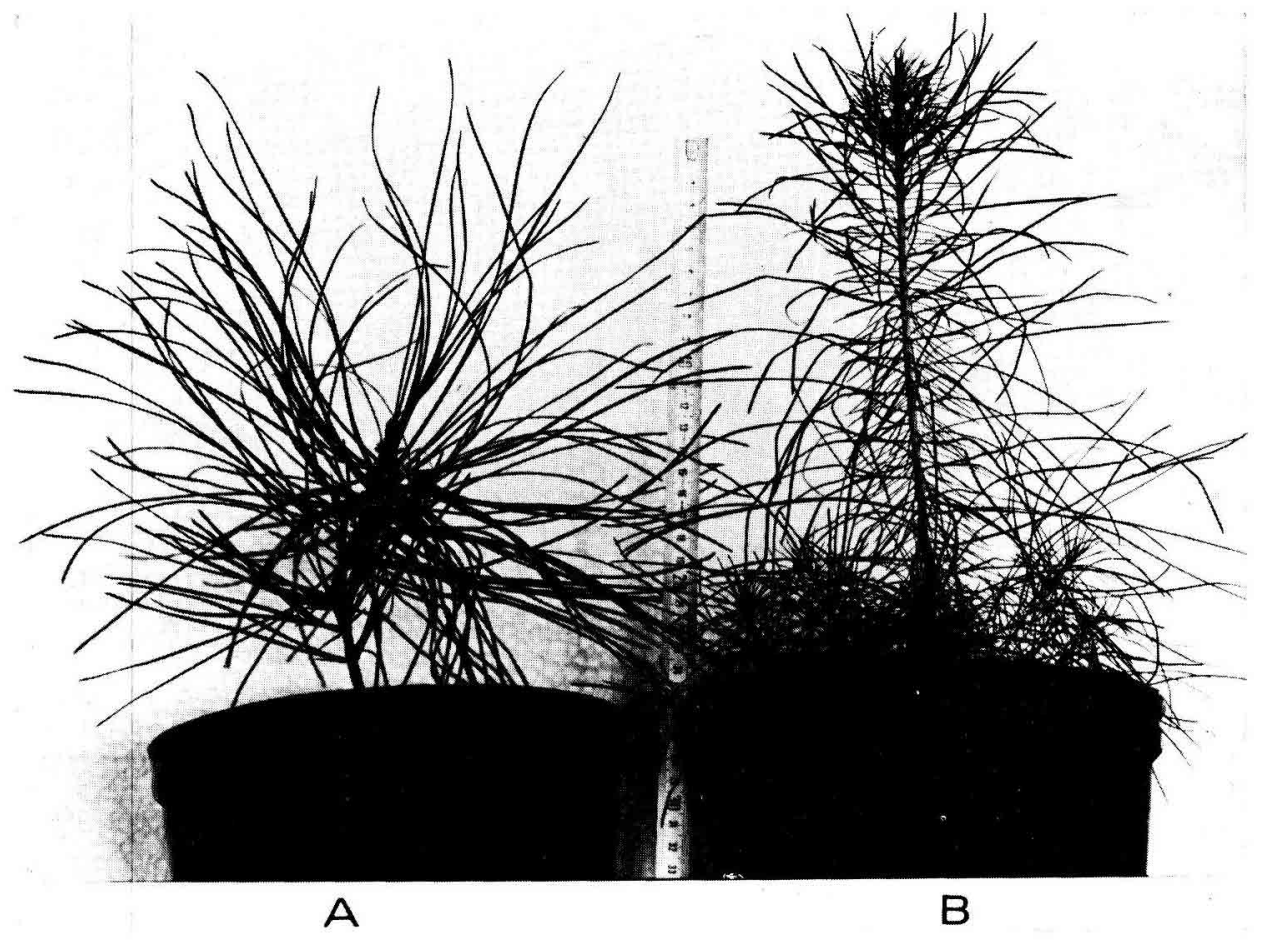

PHO,O 7

Comparaison de la partie aérienne d'une bouture racinée de «brachyblaste allongé » prélevé sur un pied-mère taillé âgé de 6 ans (à gauche, A) et d'un plant in vitro (à droite, B), après 6 mois de repiquage en serre (voir texte)

Differences in aerial parts between a hardwood cutting from a 6-year old mother-plant (left, A) and a test-tube seedling (right, B) 6 months afier greenhouse transplantation (see text)

Du point de vue génétique, la méthode in vitro offre les mêmes "garanties » contre les mutants ou les variants que les techniques de multiplication traditionnelles par bouturage, marcottage ou greffage, dans la mesure où on ne l'applique qu'à des méristèmes préformés et où on ne met en cuvre des facteurs physiologiques que dans des limites rencontrées dans la nature.

Au moment où des semences sélectionnées commencent à être récoltées dans les vergers à graines, des clones obtenus à partir de ces semences seront très utiles pour gagner du temps dans les tests de descendance et pour pouvoir apprécier au plus juste les «gains génétiques » effectifs en éliminant l'influence des micro-sites par des essais sur le terrain plus diversifiés.

Ainsi, l'utilisation des cultures in vitro pourra trouver sa place à brève échéance dans les schémas habituels de la sélection. 


\title{
Summary
}

\author{
In vitro micropropagation of Pinus pinaster
}

Pinus pinaster is so far propagated by seeds only ; the traditional vegetative multiplication procedures cannot be used on a large scale. We investigate in vitro tissue culture techniques to get clonal propagation quickly from selected genotypes and an efficient method of mass propagation on a long term period.

A cytokinin stimulus (benzyladenin, $2 \mathrm{mg} / \mathrm{l}$ ) promotes new bud formation on excised embryos and apical parts of 6 week-old seedlings; results are reproducible. After excision of these new buds from the primary explants, an auxin stimulus (naphtylacetic acid, $0.02 \mathrm{mg} / 1$ ) promotes new root formation; but only axillary buds excised from apical parts of seedlings rebuild whole plants in a reproducible way.

According to our experimental conditions, we can get a mean of 8 copies per seed on a 6 month delay. The method has to be improved.

Sometimes we observe dichotomous root formation in our assays; so we plan to put selected strains of mycorrhizae in test-tubes on the newly formed roots to help young trees settling.

\section{Références bibliographiques}

Boulay M., Franclet A., 1977. Recherches sur la propagation végétative du Douglas : Pseudotsuga menziesii (Mirb.) Franco. Possibilités d'obtention de plants viables à partir de la culture in vitro de bourgeons de pieds-mères juvéniles. C.R. Acad. Sc. Paris, 284, $1405-1407$.

Campbell R.A., Durzan D.J., 1975. Induction of multiple buds and needles in tissue cultures of Picea glauca. Can. J. Bot., 53, 1652-1657.

Campbell R.A., Durzan D.J., 1976. Vegetative propagation of Picea glauca by tissue culture. Can. J. For. Res., 6, 240-243.

Chalupa V., 1975. Induction of organogenesis in forest tree tissue cultures. Communications instituti forestalis, 9, 39-50.

Chalupa V., Durzan D.J., Vithayasal C., 1976. Growth and metabolism of cells and tissue of jack pine (Pinus banksiana). 2. The quantitative analysis of the growth of callus from hypocotyls and radicles. Can. J. Bot., 54, 446-455.

Cheng T.Y., 1976. Vegetative propagation of western hemlock (Tsuga heterophylla) through tissue culture. Plant Cell Physiol., 17, 1347-1350.

Cheng T.Y., Voqui T.H., 1977. Regeneration of Douglas Fir plantlets through tissue culture. Science, 198, 306-307.

Coleman W. Thorpe T.A., 1977. In vitro culture of western red cedar (Thuya plicata Donn.). I. Plantlet formation. Bot. Gaz., 138, 298-304.

Cornu D., Delrans S., Garbaye J., Le Tacon F., 1977. Recherche des meilleures conditions d'enracinement des boutures herbacées de chêne rouvre lQuercus petraea (M.) Liebl.] et de hêtre (Fagus silvatica L.). Ann. Sci. Forest., 34, 1-16.

David A., DAvid H., 1977. Manifestations de diverses potentialités organogènes d'organes ou de fragments d'organes de Pin maritime (Pinus pinaster Sol.) en culture in vitro. C.R. Acad. Sc. Paris., 284, 627-630.

David H., Isemukali K., David A.. 1978. Obtention de plants de Pin maritime (Pinus pinaster Sol.) à partir de brachyblastes ou d'apex caulinaires de très jeunes sujets cultivés in vitro. C.R. Acad. Sc. Paris, 287, 245-248.

Franclet A., 1977. Manipulation des pieds-mères et amélioration de la qualité des boutures. A.F.O.C.E.L., Etudes et Recherches, 8, 1-21. 
Heller R., 1953. Recherches sur la nutrition minérale des tissus végétaux cultivés in vitro. Ann. Sci. Nat. Bot. Biol. Vég., 14, 1-223.

KonAr R.N., 1975. In vitro studies of Pinus. II. The growth and morphogenesis of cell culiures from Pinus gerardiana. Phytomorph., 25, 55-59.

Margara J., Rancillac M., 1966. Observations préliminaires sur le rôle du milieu nutritif dans l'initiation florale des bourgeons néoformés in vitro chez Cichorium intybus $\mathbf{L}$. C.R. Acad. Sci. Paris, 263, 1455-1458.

Mott R.L., Smeljzer R.H., Mehra-Palta A., Zobel B.J., 1977. Production of forest trees by tissue culture. Tappi, 60, 62-64.

Murashige T., Skoog F., 1962. A revised medium for rapid growth and bioassays with tobacco tissue cultures. Physiol. Plant., 15, 473-497.

ReILly K., Brown C.L., 1976. In vitro studies of bud and shoot formation in Pinus radiata and Pseudotsuga menziesii. Georgia For. Res. Paper, 86, 1-9.

REILly K., WASHER J., 1977. Vegetative propagation of radiata pine by tissue culture. Plantlet formation from embryonic tissue. New Zealand J. For. Sc., 7, 199.

Risser P.G., White P.R., 1964. Nutritional requirements of spruce tumor cells in vitro. Physiol. Plant., 17, 620-635.

SOMmer H.E., 1975. Differentiation of adventitious buds on Douglas-Fir embryos in vitro. Reprint from. Proc. Intern. Plant Propagator Soc., 25, 125-127.

Sommer H.E., Brown C.L., 1974. Plantlet formation in pine tissue cultures. Am. J. Bot. Supp., 61, 11.

Sommer H.E., Brown C.L., Kormanik P.P., 1975. Differentiation of plantlets in longleaf pine (Pinus palustris Mill.) tissue cultured in vitro. Bot. Gaz., 136, 196-200.

Webb K.J., Street H.E., 1977. Morphogenesis in vitro of Pinus and Picea. Acta Hort., 78, 259-269. 